\title{
REVIEW
}

\section{Health technology assessment review: Remote monitoring of vital signs - current status and future challenges}

Vishal Nangalia', David R Prytherch² and Gary B Smith3,4*

\begin{abstract}
Recent developments in communications technologies and associated computing and digital electronics now permit patient data, including routine vital signs, to be surveyed at a distance. Remote monitoring, or telemonitoring, can be regarded as a subdivision of telemedicine - the use of electronic and telecommunications technologies to provide and support health care when distance separates the participants. Depending on environment and purpose, the patient and the carer/system surveying, analysing or interpreting the data could be separated by as little as a few feet or be on different continents. Most telemonitoring systems will incorporate five components: data acquisition using an appropriate sensor; transmission of data from patient to clinician; integration of data with other data describing the state of the patient; synthesis of an appropriate action, or response or escalation in the care of the patient, and associated decision support; and storage of data. Telemonitoring is currently being used in communitybased healthcare, at the scene of medical emergencies, by ambulance services and in hospitals. Current challenges in telemonitoring include: the lack of a full range of appropriate sensors, the bulk weight and size of the whole system or its components, battery life, available bandwidth, network coverage, and the costs of data transmission via public networks. Telemonitoring also has the ability to produce a mass of data - but this requires interpretation to be of clinical use and much necessary research work remains to be done.
\end{abstract}

\section{Introduction}

Remote monitoring, or telemonitoring, can be regarded as a subdivision of telemedicine - the use of electronic and telecommunications technologies to provide and support health care when distance separates the participants [1]. Telemonitoring involves the use of audio, video, and other telecommunications and electronic information processing technologies to monitor patient status at a distance. The patient and the carer/system surveying, analysing or interpreting the data could be a few feet apart, but more often they will be in different areas of the same building, different buildings or different towns. In theory, they could even be in different countries or continents. The first case of direct transmission of a patient variable was that of an electrocardiograph (ECG) in 1905 by the inventor of the ECG, Einthoven [2]. However, the routine use of telemonitoring began in 1961 when the ECG, respiratory rate, electro-oculogram and galvanic skin response of the first human in space, Yuri Gagarin, were continuously monitored by doctors on earth. Figure 1 shows typical ECG tracings from Neil Armstrong, Buzz Aldrin and Michael Collins, received at the Mission Control Center approximately 384,467 kilometres away, during various periods of the Apollo 11 mission to the moon in 1969.

This review will provide a broad overview of this resurgent field of medical remote monitoring and will describe the components of telemedicine, the current clinical utilisation and the field's obvious challenges. Where possible, the article provides the appropriate references to allow the interested reader to obtain additional information.

\section{Components of telemonitoring}

At its simplest, the monitoring of a person's vital signs involves an observer (usually a clinician) using their own senses directly (that is, without any intervening technology) to determine pulse rate, breathing rate, and so on. Added sophistication is produced by introducing simple technology such as a sphygmomanometer, stethoscope or thermometer, but still the act of monitoring is

*Correspondence: gary.smith@porthosp.nhs.uk

${ }^{3}$ TEAMS Centre, Queen Alexandra Hospital, Portsmouth PO6 3LY, UK

Full list of author information is available at the end of the article 


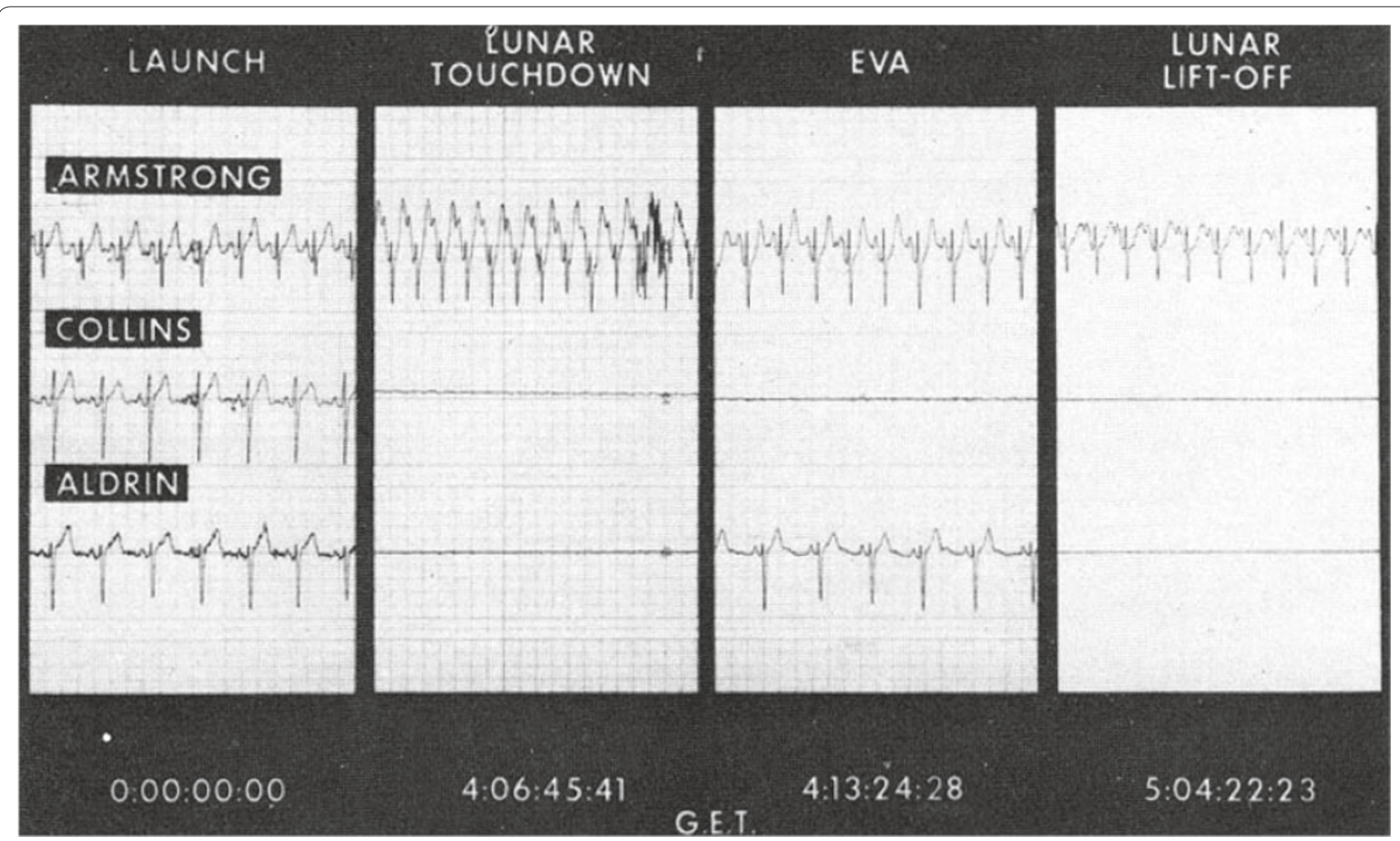

Figure 1. Electrocardiograph signal received at Mission Control during various periods of the Apollo 11 mission (NASA). (http://history. nasa.gov/SP-368/p492b.htm)

performed directly by the clinician. All remaining processes, up to and including synthesising the appropriate response, occur in the clinician's brain. The advance of technology, with the final stage of remote monitoring, has separated the various links in the chain between measuring and acting, and made explicit the chain of events, actions, processing and decisions linking the patient and the clinician.

The various links in this chain may include the following: data acquisition using an appropriate sensor; transmission of these data from patient to clinician; integration of the data with other data describing the state of the patient; synthesis of an appropriate action, or response or escalation in the care of the patient, and associated decision support; and data storage. The second, third and fourth items can occur in any order and may be repeated at different stages. These stages will now be considered in detail.

\section{Data acquisition using an appropriate sensor}

Sensors, their modes of action, and the signals (vital signs) they measure are well known and are beyond the scope of this article. However, it is worth noting that newer modalities of measurement are emerging [3]. Any physiological parameter that can be measured can theoretically be telemonitored. Table 1 lists those variables for which this has been successfully achieved [4]. Measurements from sensors may be continuous or intermittent. The time to the next measurement may be determined by the last value. The sensor may be remote from the patient (for example, using Doppler radar to count breathing rate) [3] or intermittently used by the patient [5] or even continuously worn by the patient (for example, the remote patient monitoring system is integrated within a 'smart garment') [6]. The measurement and collection of the data may be entirely automatic, or may involve a human (usually a clinician or the patient) in invoking the measurement or in performing it (for example, nurses entering vital signs data into a handheld computer) [7].

\section{The transmission of data from patient to clinician}

Depending on the setting, transmission of data can be by wired or wireless connections. Modalities include both wired and wireless computer networks, telephone networks and mobile phone networks. Systems that identify the available modalities and use them accordingly for the transmission of data are being developed. The transmission technology is the essential glue in the various possible chain topologies. Its capabilities (bandwidth, coverage, cost of use, and so on) predicate the functions and capabilities of the other components. Transmission 
Table 1. Physiological parameters that have been successfully telemonitored [5]

\begin{tabular}{l} 
Heart rate \\
Blood pressure \\
Respiratory rate \\
Temperature \\
Pulse oximetry \\
Heart sounds \\
Electrocardiograph (ECG) \\
Pacemaker parameters \\
Electroencephalogram (EEG) \\
Electromyograph (EMG) \\
Spirometry \\
Body weight physical activity \\
Fetal heart rate \\
Basal metabolic rate \\
$\mathrm{O}_{2}$ consumption \\
CO ${ }_{2}$ production \\
Blood glucose \\
Blood lactate \\
Blood ethanol \\
Intracranial pressure \\
Intravesical pressure \\
Intrauterine pressure \\
\hline
\end{tabular}

technologies will need to be chosen according to the particular use envisaged. Transmission of data from patient to clinician may be continuous or may only occur when a pre-defined exception state has occurred (for example, when a potentially dangerous heart rhythm is detected) [8] or when connectivity is available.

Currently, different systems tend to use proprietary standards for transmission of data. As such systems become more common place, standards such as HL7 will become more widely used to allow integration and total systems building. Governments have set aside portions of the electromagnetic spectrum for the specific use of wireless telemetry, though these are not always standardised across international regions and there are severe bandwidth limitations and interference issues. Therefore, most medical device companies develop for the internationally agreed 2.4 to $2.5 \mathrm{GHz}$ industrial, scientific and medical band (ISM) [9], though, since this is not medicine-specific, it is open to possible interference and overcrowding.

Wireless transmission protocols in use include wi-fi $(802.11 \mathrm{a} / \mathrm{b} / \mathrm{g} / \mathrm{n})$ at $2.45 \mathrm{GHz}$ and $5.8 \mathrm{GHz}$, and Bluetooth at approximately $2.45 \mathrm{GHz}$. Newer low-power, though lower-bandwidth, protocols that are also gaining favour include ANT [10] and Zigbee [11]. The Continua Health
Alliance [12] has been formed to standardise both the protocols for transmission of medical data and the devices themselves, so devices can securely and reliably communicate with each other but this is at an early stage.

\section{Integration of the data with other data describing the state} of the patient

This may be done by a computer or a clinician, or both. Computer integration and/or analysis of data and their synthesis into information on which to act can happen anywhere in the chain and may be distributed across it. Amongst other things, this depends upon what data are being transmitted along the chain, which itself depends on the available bandwidth and its cost. Raw data could be transmitted (for example, three-lead ECG) or simply the heart rate; a full set of vital signs could be transmitted or simply a derived value such as an early warning score [13] or other index of patient severity of illness [14].

The detection of a particular patient state as a result of computer integration and/or analysis of data and their synthesis may be used to trigger transmission of the data themselves [8]. These are all inter-related engineering decisions specific to a particular application.

Synthesis of an appropriate action, or response or escalation in the care of the patient, and associated decision support

This depends on context. In hospital, it might be a decision to admit to an ICU or to call a rapid response team; in the community, the action could be to arrange a visit by a community nurse. Such a decision could be made by an 'intelligent' system but at present would certainly involve human input. Importantly, though, such 'systems' could push the data to the responsible clinician for a decision to be made when pre-determined criteria had been satisfied, removing the need for continuous human monitoring. What such escalation (or deescalation) criteria should be is both context-dependent and probably unknown. The extent of synthesis and decision support ranges from applying the above criteria for escalating clinical input to simply making background contextual information available to the responsible clinician to reduce diagnostic and decision errors, and improve patient safety and quality of care [15].

\section{Data storage}

At one extreme this may be local storage of data in the sensing device to allow, for example, a breathing rate to be determined prior to transmission or the short-term storage of data to allow the data prior to a critical event to be transmitted as supporting information along with notification of the critical event [8]. At the other extreme, it could be the formation of a large database of vital signs to determine and validate calling criteria for rapid response team activation [7]. Such data are almost certain 
to become an essential part of the electronic patient record. Medico-legal as well as contractual and billing issues will demand the storage of the majority of these data.

\section{Clinical use of telemonitoring}

Telemonitoring is being used in the home, at the scene of a medical emergency, in transit via the ambulance service and in the hospital.

\section{Home}

In the home, telemonitoring is characterised by a patient being monitored by a number of devices and the subsequent, real time or delayed transmission of derived data via the domestic or mobile telephone service to a remote monitoring service or healthcare provider. These devices may monitor physiological data (for example, pulse, blood pressure, $\mathrm{SpO}_{2}$, blood glucose) or the performance of equipment such as implantable defibrillators or pacemakers [16,17]. Most commonly, telemonitoring is used for the distant surveillance of patients with chronic disease, such as chronic heart failure, chronic obstructive pulmonary disease and diabetes mellitus. However, fetal heart rates and the level of activity of elderly people have also been monitored $[4,18]$. The same type of technology may also be used to record a patient's subjective response to specific pre-set questions about their health [5]. Table 2 lists a selection of studies with positive outcomes attributed to telemonitoring. It has been estimated that the use of remote monitoring of chronic disease to prevent deterioration by early detection and intervention in the community could save approximately $\$ 197$ billion in the USA over the next 25 years [19].

However, other studies have not shown any change in measured parameters with home-based monitoring and intervention for asthma [20] or hypertension [21]. Systematic reviews on chronic disease management and telemonitoring, although acknowledging the potential benefit of telemonitoring, highlight the need for further research [22-24]. Interpretation of the significance of the reported results of most pre-hospital telemonitoring studies is difficult because not only has the frequency of vital sign measurement been arbitrarily chosen - ranging from continuous to symptom-based [21,25-36] - but medical review and intervention based on the collected data also varied from immediately based on alarms to monthly [21,27-30,34,36-38].

\section{Disaster medicine}

Systems are being developed that would enable emergency medical services to tag and physiologically monitor large numbers of patients at a remote site, that is, the site of the disaster or a triage centre [39]. Such systems would provide first responders, disaster command centres and supporting hospitals with medical data to track and monitor the condition of up to thousands of victims on a moment-to-moment basis using vital signs monitoring and location tagging (similar to global positioning system tagging).

\section{Ambulance services}

Use of telemedicine in ambulances has so far focussed primarily on patients suspected of suffering a myocardial infarction. ECG data from these patients has been transmitted to a designated hospital and a decision is then for either pre-hospital thrombolysis [40] or redirecting the ambulance to a centre for primary angioplasty [41], both of which have been shown to reduce the time to treatment compared to traditional in-hospital assessment. Other parameters transmitted from ambulances include non-invasive blood pressure, arterial oxygen saturation, blood glucose concentration and body temperature [42].

\section{In hospital}

In hospital, the interest in telemonitoring has been driven by the need to balance the conflicting requirements posed by increased population age, increased patient severity of illness, increased incidence of concurrent illness, reduced staffing levels and raised patient expectation regarding patient safety. Telemonitoring could be used in any area of a hospital, but is perhaps most pertinent in critical care areas and the general wards.

\section{Critical care areas}

In the USA, VISICU, a Philips healthcare company, has implemented over 30 remote ICU programmes, in which intensivists and physicians provide supplemental monitoring and management of ICU patients at workstations in an off-site, centralized facility (the eICU). Bedside monitor data, lab results, patient treatment charts, ventilator and other equipment settings and outputs from audiovisual equipment in the ICU patient rooms are available to the eICU staff, who also have access to physician note- and order-writing applications. When the eICU team is allowed full and direct management of the patient, these systems have been reported to reduce mortality by up to $33 \%$ [43], number of ventilator days by up to $25 \%$ [43] and length of stay in the ICU by up to $17 \%$ [44]. A criticism of the eICU is that these benefits may only be apparent in an environment where there is a shortage in the number of intensivists to adequately provide an onsite 24/7 specialist-led service. Other descriptions of the use of telemonitoring in critical care include the provision of support for patients requiring mechanical ventilation at home [45], which has proved to be successful in the weaning of a patient from home mechanical ventilation without onsite specialist help [46]. 
Table 2. Telemonitoring studies with a positive outcome

\begin{tabular}{|c|c|c|c|c|c|c|}
\hline Paper & Setting & Disease & $\begin{array}{l}\text { Parameters } \\
\text { measured } \\
\text { (frequency) }\end{array}$ & $\begin{array}{l}\text { Transmission } \\
\text { frequency }\end{array}$ & $\begin{array}{l}\text { Review } \\
\text { frequency }\end{array}$ & Outcome \\
\hline $\begin{array}{l}\text { Breslow } \\
2007 \\
{[43,44]}\end{array}$ & $\begin{array}{l}\text { In hospital - } \\
\text { ICU }\end{array}$ & $\begin{array}{l}\text { Multiple - all } \\
\text { critically ill } \\
\text { patients }\end{array}$ & $\begin{array}{l}\text { Multiple } \\
\text { continuously; } \\
\text { all measured } \\
\text { parameters }+ \\
\text { video monitoring }\end{array}$ & Continuously & Continuously & $\begin{array}{l}\text { Reduced mortality by up to } 33 \% \text {, number of ventilator } \\
\text { days by up to } 25 \% \text {, length of stay by up to } 17 \%\end{array}$ \\
\hline $\begin{array}{l}\text { Antonicelli } \\
\text { et al. } 2008 \\
{[30]}\end{array}$ & Community & $\begin{array}{l}\text { Chronic heart } \\
\text { failure (CHF) }\end{array}$ & $\begin{array}{l}\text { BP (daily), ECG } \\
\text { (weekly), body } \\
\text { weight (weekly), } \\
\text { 24-h urine output } \\
\text { (weekly) }\end{array}$ & Daily & Weekly & $\begin{array}{l}\text { Telecare versus usual care: decreased hospital } \\
\text { readmission } 9 \text { versus } 26(P<0.01) \text {; trend towards } \\
\text { decreased mortality } 3 \text { versus } 5 \text {; total patients } 28 \text { versus } \\
29(N=57)\end{array}$ \\
\hline $\begin{array}{l}\text { Fursse et al. } \\
2008[29]\end{array}$ & Community & $\begin{array}{l}\text { Diabetes, } \\
\text { hypertension, } \\
\text { CHF }\end{array}$ & $\begin{array}{l}\text { Blood glucose } \\
\text { (daily), } \mathrm{BP} \text { (daily), } \\
\mathrm{SpO}_{2} \text { (daily) }\end{array}$ & Daily & $\begin{array}{l}\text { On alerts, } \\
\text { regularly - } \\
\text { not specified }\end{array}$ & $\begin{array}{l}\text { Mean reductions of } 11 \mathrm{mmHg} \text { systolic and } 2 \mathrm{mmHg} \\
\text { diastolic in patients with } \mathrm{CHF}, 0.4 \% \mathrm{HbA} 1 \mathrm{c} \text { in those with } \\
\text { diabetes, and } 12 \mathrm{mmHg} \text { systolic and } 2 \mathrm{mmHg} \text { diastolic } \\
\text { in those with hypertension (no control group; } \mathrm{N}=29 \text { ) }\end{array}$ \\
\hline $\begin{array}{l}\text { Green et al. } \\
2008[31]\end{array}$ & Community & Hypertension & BP (twice weekly) & Twice weekly & Fortnightly & $\begin{array}{l}\text { Higher proportion of patients (after } 12 \text { months) whose } \\
\text { BP was controlled (<140/90); telemonitored group 56\% } \\
\text { versus usual care } 31 \% \text { ( } 80 \% \text { increase; } N=778 \text { ) }\end{array}$ \\
\hline $\begin{array}{l}\text { Kisner et al. } \\
2008 \text { [61] }\end{array}$ & $\begin{array}{l}\text { In hospital - } \\
\text { ward }\end{array}$ & $\begin{array}{l}\text { Atrial fibrillation } \\
\text { post CABG }\end{array}$ & $\begin{array}{l}\mathrm{SpO}_{2} \\
\text { (continuously) }\end{array}$ & Continuously & On alerts & $\begin{array}{l}\text { Incidence of atrial fibrillation in telemonitored group } \\
\text { was } 14 \% \text { versus } 26 \% \text { (prior to telemonitoring; } P=0.016 \text {; } \\
N=119 ; \text { control cohort }=238 \text { ) }\end{array}$ \\
\hline $\begin{array}{l}\text { Morguet } \\
\text { et al. } 2008 \\
{[33]}\end{array}$ & Community & $\mathrm{CHF}$ & $\begin{array}{l}\text { Weight (daily), BP } \\
\text { (daily), pulse rate } \\
\text { (daily), ECG (on } \\
\text { request) }\end{array}$ & Daily & $\begin{array}{l}\text { Twice weekly, } \\
\text { on alerts }\end{array}$ & $\begin{array}{l}50 \% \text { reduction in hospital admissions ( } 38 \text { versus } 77 / 100 \\
\text { patient years, } P=0.034), 54 \% \text { reduction in hospital } \\
\text { length of stay }(317 \text { versus } 693 \text { days } / 100 \text { patient years; } \\
P<0.0001)(N=128)\end{array}$ \\
\hline $\begin{array}{l}\text { Nakamoto } \\
\text { et al. } 2008 \\
{[63]}\end{array}$ & Community & $\begin{array}{l}\text { Hypertension: } \\
\text { drug trial of } \\
\text { temlisartan versus } \\
\text { amlodipine }\end{array}$ & BP (twice daily) & Twice daily & End of study & $\begin{array}{l}\text { Evening systolic BP reductions higher in telmisartan } \\
\text { versus amlodipine group }(13 \pm 3 \text { versus } 6 \pm 3 \mathrm{mmHg}) \text {; } \\
\text { non-significant differences in morning BP reduction } \\
\text { between both groups; better daytime normalisation } \\
\text { with telmisartan }(\mathrm{N}=40)\end{array}$ \\
\hline $\begin{array}{l}\text { Nielsen et } \\
\text { al. } 2008 \\
{[27]}\end{array}$ & Community & ICD, pacemaker & ECG (continuously) & Daily, on alerts & On alerts & $\begin{array}{l}26 \% \text { of unplanned clinic visits initiated by } \\
\text { telemonitored data }(N=260)\end{array}$ \\
\hline $\begin{array}{l}\text { Ricci et al. } \\
2008 \text { [28] }\end{array}$ & Community & ICD, pacemaker & ECG (continuously) & Daily, on alerts & $\begin{array}{l}\text { Fortnightly, } \\
\text { on alerts }\end{array}$ & $\begin{array}{l}37 \% \text { of patients had changes to their medication, } \\
\text { device reprogramming, or were called in for further } \\
\text { investigations ( } N=117)\end{array}$ \\
\hline $\begin{array}{l}\text { Woodend } \\
\text { et al. } 2008 \\
{[34]}\end{array}$ & Community & $\begin{array}{l}\text { Angina, heart } \\
\text { failure }\end{array}$ & $\begin{array}{l}\text { BP (daily), weight } \\
\text { (daily), ECG (not } \\
\text { specified) }\end{array}$ & Daily & Weekly & $\begin{array}{l}32 \% \text { reduction in hospital admission ( } 0.4 \text { versus } 0.59 \\
\text { hospital readmission rate per patient, } P=0.048) ; 46 \% \\
\text { reduction in length of stay in hospital if readmitted } \\
(2.11 \text { versus } 3.93 \text { days, } P=0.038)(N=249)\end{array}$ \\
\hline $\begin{array}{l}\text { Parati et al. } \\
2009[35]\end{array}$ & Community & Hypertension & BP (not specified) & Not specified & On alerts & $\begin{array}{l}\text { Increased daytime } \mathrm{BP} \text { normalization }(<130 / 90), 62 \% \\
\text { versus } 50 \%(P<0.05) \text {; less frequent treatment changes, } \\
9 \% \text { versus } 14 \%(P<0.05)(\mathrm{N}=228)\end{array}$ \\
\hline
\end{tabular}

BP, blood pressure; $C A B G$, coronary artery bypass graft; $C H F$, chronic heart failure; $E C G$, electrocardiograph; ICD, implantable cardioverter-defibrillator.

Systems that monitor patients' physiological parameters during home hemodialysis also exist [47].

Remote monitoring of vital signs of ward patients provides the possibility of obtaining pre-ICU data - even to the point of using these data to decide if ICU admission is required. It may also allow earlier, safe discharge of patients from the ICU as they can be reliably remotely monitored by ICU staff. Perhaps, most interestingly, it potentially allows ICU staff to survey the whole population of monitored in-patients and to intervene as necessary - a technology-enabled pro-active outreach service [7].

\section{Ward patients}

Many hospitalised patients suffering adverse events (for example, in-hospital cardiac arrest, unanticipated ICU admission or death) exhibit physiological deterioration in the period before the event [48-50]. Sometimes this is detected, but often there is insufficient monitoring [51-55]. For example, the 2007 National Confidential Enquiry into Patient Outcome and Death report [54] noted that 'not only are appropriate observations performed less often than is desirable, when they are performed, their frequency is inappropriately low in a significant proportion of patients.' Other failures in the 
system of recognising and responding to patient deterioration include a failure to call for experienced help and a failure of responders to respond [48-51].

Outreach/medical emergency team data appear to indicate that early identification and intervention of deteriorating patients reduces the incidence of adverse events. In one multicentre study Chen and colleagues [56] analyzed 11,242 serious adverse events and 3,700 emergency team calls and found for every $10 \%$ of increase in the proportion of early emergency team calls there was a 2.0 reduction per 10,000 admissions in unexpected cardiac arrests (95\% confidence interval (CI) 2.6 to 1.4 ), a 2.2 reduction in overall cardiac arrests (95\% CI 2.9 to 1.6), and a 0.94 reduction in unexpected deaths (95\% CI 1.4 to 0.5 ).

It is now advised that a clear physiological monitoring plan, which details the parameters to be monitored and the frequency of observations, should be made for each patient, and that there should be a graded response to patient severity of illness $[7,53]$. Other recent reports also recommend an increase in the range and frequency of physiological parameters monitored in general ward patients [51-55]. This could be achieved by increasing levels of nurse staffing, as this has been shown to reduce adverse outcomes [57], but there are limits to the extent to which nursing numbers can be increased. However, technology can enable the continuous capture and transmission of physiological parameters and the advent of early warning systems allows for a mechanism of automatic analysis of these signals, theoretically enabling the clinical expertise of medical professionals to be focussed on those patients who are at greatest risk of deterioration. Telemonitoring technology therefore has the potential to increase patient care and is thus regarded as an integral part of the UK National Health Service Connecting for Health Programme [58].

There are many publications from ICUs, high dependency units or cardiac care units that describe data telemetry from a bed-bound patient to the nurses' station. However, descriptions of the use of such technology in the general wards of hospitals are rare. Cale [59] has described the hospital-wide implementation of a wireless telemonitoring system in a Californian hospital that transmits patient parameters to a 'war room', where these are monitored by biomedical technicians 24 hours a day. The use of a wireless pulse oximeter in a Zurich hospital $[60,61]$ is claimed to reduce the incidence of atrial fibrillation (14\% versus $26 \%$ prior to telemonitoring, $P=0.016)$ in coronary artery bypass graft patients by early detection of desaturation and implementation of oxygen therapy. A unique characteristic of this system is that it either pages the doctor directly or sends an SMS text message to their mobile phone alerting them of the desaturation and providing a history of the event. In the
UK, nurses in some hospitals use the VitalPAC system for collecting routine vital signs data at the bedside using standard personal digital assistants (PDAs) wirelessly linked to the hospital's intranet system. Here raw and derived data are integrated with patient demographic and laboratory information, allowing raw physiology data, early warning scores, vital signs charts and oxygen therapy records to be made instantaneously available to any member of the hospital healthcare team [7].

\section{Some obvious challenges}

Currently, the technology for telemonitoring is far from mature and there are still technological issues to be addressed. These include: the lack of a full range of appropriate sensors; the bulk weight and size of the whole system or its components (particularly in relation to patient-worn systems); the identification of invalid data (for example, from sensors that become detached/ displaced); battery life; available bandwidth; network coverage; and the costs of data transmission via public networks.

There will also be challenges for adoption of such systems because individuals may see constant physiological surveillance as intrusive. As with genetics testing, there may even be insurance-related issues [62]. There are also potential cultural problems to be tackled in relation to the deployment of such technology in healthcare organisations, as they produce requirements for new ways of working. Another major problem is that telemonitoring has the ability to produce a mass of data that require interpretation to be of use. New data analysis methods therefore need to be devised and validated. Mistakes in this analysis could have medico-legal consequences.

However, despite all the potential hurdles, it is likely to be only a matter of time before smart systems continuously monitor every patient from the moment they are admitted to the point of discharge from hospital (and possibly beyond).

\section{Abbreviations}

$\mathrm{Cl}=$ confidence interval; ECG = electrocardiograph.

\section{Competing interests}

VitalPAC ${ }^{\mathrm{TM}}$ is a collaborative development of The Learning Clinic Ltd and Portsmouth Hospitals NHS Trust. Professor Gary Smith's wife and Dr David Prytherch's wife are shareholders in The Learning Clinic Ltd. Professor Smith and Dr Prytherch are engaged in research with McLaren Applied Technologies and Laerdal Medical who both manufacture patient monitoring devices.

\section{Author details}

'Academic Clinical Fellow, Centre for Anaesthesia, University College London Hospital, Room 436, 4th floor, 74 Huntley St, London WC1E 6AU, UK. ${ }^{2}$ Clinical Scientist, Portsmouth Hospitals NHS Trust, TEAMS Centre, Queen Alexandra Hospital Portsmouth PO6 3LY, UK. 3Professor, Portsmouth Hospitals NHS Trust, TEAMS Centre, Queen Alexandra Hospital Portsmouth PO6 3LY. ${ }^{4}$ Professor, The School of Health \& Social Care, Bournemouth University, Royal London House, Christchurch Road, Bournemouth, Dorset BH1 3LT, UK 
Published: 24 September 2010

\section{References}

1. Field MJ: Telemedicine: A guide to assessing telecommunications in healthcare. J Digit Imaging 1997, 10(3 Suppl 1):28.

2. Einthoven WL: Télécardiogramme. Arch Int Physio/ 1906, 4:132-164.

3. Smith G, Parry D, Farrell S, Woodward L, Prytherch D, Harrison S, Hirsch N: Validation of a novel radar-based breathing rate measurement device in human volunteers. Resuscitation 2008, 77:14-15.

4. Meystre S: The current state of telemonitoring: A comment on the literature. Telemed J E Health 2005, 11:63-69.

5. Health Buddy [http://www.healthbuddy.com/content/language1/ html/5583_ENU_XHTML.aspx]

6. Clarenbach CF, Senn O, BrackT, Kohler M, Bloch KE: Monitoring of ventilation during exercise by a portable respiratory inductive plethysmograph. Chest 2005, 128:1282-1290.

7. Smith GB, Prytherch DR, Schmidt P, Featherstone PI, Knight D, Clements G, Mohammed MA: Hospital-wide physiological surveillance-a new approach to the early identification and management of the sick patient. Resuscitation 2006, 71:19-28.

8. Pollack CV: Wireless cardiac event alert monitoring is feasible and effective in the emergency department and adjacent waiting areas. Crit Pathw Cardiol 2009, 8:7-11.

9. ISM band [http://en.wikipedia.org/wiki/ISM_band]

10. ANT [http://www.thisisant.com/]

11. Zigbee Alliance [http://www.zigbee.org/]

12. Continua Health Alliance [http://www.continuaalliance.org/index.html]

13. Morgan RJM, Williams F, Wright MM: An early warning scoring system for detecting developing critical illness. Clin Intensive Care 1997, 8:100.

14. Tarassenko L, Hann A, Young D: Integrated monitoring and analysis for early warning of patient deterioration. Br J Anaesth 2006, 97:64-68.

15. Isabel: Clinical Decision Support System [http://www.isabelhealthcare.com/ home/default]

16. Medtronic Carelink [http://www.medtronic.com/your-health/tachycardia/ device/our-implantable-defibrillators/carelink/index.htm]

17. Marzegalli M, Lunati M, Landolina M, Perego GB, Ricci RP, Guenzati G, Schirru M, Belvito C, Brambilla R, Masella C, Di Stasi F, Valsecchi S, Santini M: Remote monitoring of CRT-ICD: The multicenter italian carelink evaluation - ease of use, acceptance, and organizational implications. Pacing Clin Electrophysio/ 2008, 31:1259-1264.

18. Di Lieto A, De Falco M, Campanile M, Papa R, Torok M, Scaramellino M Pontillo M, Pollio F, Spanik G, Schiraldi P, Bibbò G: Four years' experience with antepartum cardiotocography using telemedicine. J Telemed Telecare 2006, 12:228-233.

19. Litan RE: Vital Signs Via Broadband: Remote Health Monitoring Transmits Savings, Enhances Lives [http://www.betterhealthcaretogether.org/www/ docs/broadband.pdf]

20. Willems DC, Joore MA, Hendriks JJ, Nieman FH, Severens JL, Wouters EF: The effectiveness of nurse-led telemonitoring of asthma: results of a randomized controlled trial. J Eval Clin Pract 2008, 14:600-609.

21. Madsen LB, Kirkegaard P, Pedersen EB: Blood pressure control during telemonitoring of home blood pressure. A randomized controlled trial during 6 months. Blood Press 2008, 17:78-86.

22. Jaana M, Paré G: Home telemonitoring of patients with diabetes: a systematic assessment of observed effects. J Eval Clin Pract 2007, 13:242-253.

23. Chaudhry SI, Phillips CO, Stewart SS, Riegel B, Mattera JA, Jerant AF, Krumholz HM: Telemonitoring for patients with chronic heart failure: a systematic review. J Card Fail 2007, 13:56-62.

24. Paré G, Jaana M, Sicotte $\mathrm{C}$ : Systematic review of home telemonitoring for chronic diseases: the evidence base. J Am Med Inform Assoc 2007, 14:269-277.

25. de Jongste JC, Carraro S, Hop WC, CHARISM Study Group, Baraldi E: Daily telemonitoring of exhaled nitric oxide and symptoms in the treatment of childhood asthma. Am J Respir Crit Care Med 2009, 179:93-97.

26. Masella C, Zanaboni P, Di Stasi F, Gilardi S, Ponzi P, Valsecchi S: Assessment of a remote monitoring system for implantable cardioverter defibrillators. J Telemed Telecare 2008, 14:290-294

27. Nielsen JC, Kottkamp H, Zabel M, Aliot E, Kreutzer U, Bauer A, Schuchert A Neuser H, Schumacher B, Schmidinger H, Stix G, Clémenty J, Danilovic D, Hindricks G: Automatic home monitoring of implantable cardioverter defibrillators. Europace 2008, 10:729-735

28. Ricci RP, Morichelli L, Santini M: Home monitoring remote control of pacemaker and implantable cardioverter defibrillator patients in clinical practice: Impact on medical management and health-care resource utilization. Europace 2008, 10:164-170.

29. Fursse J, Clarke M, Jones R, Khemka S, Findlay G: Early experience in using telemonitoring for the management of chronic disease in primary care. J Telemed Telecare 2008, 14:122-124.

30. Antonicelli R, Testarmata P, Spazzafumo L, Gagliardi C, Bilo G, Valentini M, Olivieri F, Parati G: Impact of telemonitoring at home on the management of elderly patients with congestive heart failure. J Telemed Telecare 2008, 14:300-305.

31. Green BB, Ralston JD, Fishman PA, Catz SL, Cook A, Carlson J, Tyll L, Carrell D, Thompson RS: Electronic communications and home blood pressure monitoring (e-bp) study: design, delivery, and evaluation framework. Contemp Clin Trials 2008, 29:376-395.

32. Paré G, Sicotte C, St-Jules D, Gauthier R: Cost-minimization analysis of a telehomecare program for patients with chronic obstructive pulmonary disease. Telemed J E Health 2006, 12:114-121.

33. Morguet AJ, Kühnelt P, Kallel A, Jaster M, Schultheiss HP: Impact of telemedical care and monitoring on morbidity in mild to moderate chronic heart failure. Cardiology 2008, 111:134-139.

34. Woodend AK, Sherrard H, Fraser M, Stuewe L, Cheung T, Struthers C: Telehome monitoring in patients with cardiac disease who are at high risk of readmission. Heart Lung 2008, 37:36-45.

35. Parati G, Omboni S, Albini F, Piantoni L, Giuliano A, Revera M, Illyes M, Mancia G; TeleBPCare Study Group: Home blood pressure telemonitoring improves hypertension control in general practice. The telebpcare study. $J$ Hypertens 2009, 27:198-203.

36. Waldmann A, Katalinic A, Schwaab B, Richardt G, Sheikhzadeh A, Raspe H: The teleguard trial of additional telemedicine care in CAD patients. 2 morbidity and mortality after 12 months. J Telemed Telecare 2008, 14:22-26.

37. Sasamura H, Nakaya H, Julius S, Takebayashi T, Sato Y, Uno H, Takeuchi M, Ishiguro K, Murakami M, Ryuzaki M, Itoh H; STAR CAST Investigators: The short treatment with the angiotensin receptor blocker candesartan surveyed by telemedicine (STAR CAST) study: Rationale and study design. Hypertens Res 2008, 31:1843-1849.

38. Liddy C, Dusseault JJ, Dahrouge S, Hogg W, Lemelin J, Humbert J, Humber J: Telehomecare for patients with multiple chronic illnesses: Pilot study. Can Fam Physician 2008, 54:58-65.

39. Gao T, Pesto C, Selavo L, Chen Y, Ko J, Lim J, Terzis A, Watt A, Jeng J, Chen B-R, Lorincz K, Welsh M. Wireless Medical Sensor Networks in Emergency Response: Implementation and Pilot Results. In Proc. Of IEEE Internationa Conference on Technologies for Homeland Security 2008. IEEE 2008:187-192.

40. McLean S, Egan G, Connor P, Flapan AD: Collaborative decision-making between paramedics and CCU nurses based on 12-lead ECG telemetry expedites the delivery of thrombolysis in ST elevation myocardial infarction. Emerg Med J 2008, 25:370-374.

41. Clemmensen P, Sejersten M, Sillesen M, Hampton D, Wagner GS, LoumannNielsen S: Diversion of st-elevation myocardial infarction patients for primary angioplasty based on wireless prehospital 12-lead electrocardiographic transmission directly to the cardiologist's handheld computer: A progress report. J Electrocardio/ 2005, 38(4 Suppl):194-198.

42. Kang J, Chun H, Shin IH, Shin SD, Suh GJ, Kim HC: Preliminary evaluation of the use of a cdma-based emergency telemedicine system. J Telemed Telecare 2006, 12:422-427.

43. Breslow MJ: Remote ICU care programs: Current status. J Crit Care 2007, 22:66-76.

44. Breslow MJ, Rosenfeld BA, Doerfler M, Burke G, Yates G, Stone DJ, Tomaszewicz P, Hochman R, Plocher DW: Effect of a multiple-site intensive care unit telemedicine program on clinical and economic outcomes: An alternative paradigm for intensivist staffing. Crit Care Med 2004, 32:31-38.

45. Vitacca M, Assoni G, Pizzocaro P, Guerra A, Marchina L, Scalvini S, Glisenti F, Spanevello A, Bianchi L, Barbano L, Giordano A, Balbi B: A pilot study of nurse-led, home monitoring for patients with chronic respiratory failure and with mechanical ventilation assistance. J Telemed Telecare 2006 $12: 337-342$

46. Vitacca M, Guerra A, Assoni G, Pizzocaro P, Marchina L, Scalvini S, Balbi B: Weaning from mechanical ventilation followed at home with the aid of a telemedicine program. Telemed J E Health 2007, 13:445-449.

47. Schlaeper C, Diaz-Buxo JA: The fresenius medical care home hemodialysis 
system. Semin Dial 2004, 17:159-161.

48. Hillman KM, Bristow PJ, Chey T, Daffurn K, Jacques T, Norman SL, Bishop GF, Simmons G: Duration of life-threatening antecedents prior to intensive care admission. Intensive Care Med 2002, 28:1629-1634.

49. McGloin H, Adam SK, Singer M: Unexpected deaths and referrals to intensive care of patients on general wards. Are some cases potentially avoidable? JR Coll Physicians Lond 1999, 33:255-259.

50. Kause J, Smith G, Prytherch D, Parr M, Flabouris A, Hillman K; Intensive Care Society (UK); Australian and New Zealand Intensive Care Society Clinical Trials Group: A comparison of antecedents to cardiac arrests, deaths and emergency intensive care admissions in australia and new zealand, and the united kingdom - the ACADEMIA study. Resuscitation 2004, 62:275-282.

51. National Patient Safety Agency: Recognising and responding appropriately to early signs of deterioration in hospitalised patients [http://www.nrls npsa.nhs.uk/resources/?entryid45=59834]

52. National Patient Safety Agency: Safer care for the acutely ill patient: Learning from serious incidents [http://www.nrls.npsa.nhs.uk/ resources/?entryid45=59828]

53. National Institute for Health and Clinical Excellence: Acutely ill patients in hospital: Recognition of and response to acute illness in adults in hospital. NICE Clinical Guideline No. 50 [http://www.nice.org.uk/CG50]

54. Emergency Admissions: A journey in the right direction? A report of the National Confidential Enquiry into Patient Outcome and Death (2007) [http://www.ncepod.org.uk/2007report1/Downloads/EA_report.pdf]

55. National Confidential Enquiry into Patient Outcome and Death: An acute problem? (2005) [http://213.198.120.192/2005aap.htm]

56. Chen J, Bellomo R, Flabouris A, Hillman K, Finfer S, MERIT Study Investigators for the Simpson Centre, ANZICS Clinical Trials Group: The relationship between early emergency team calls and serious adverse events. Crit Care Med 2009, 37:148-153.
57. Needleman J, Buerhaus P, Mattke S, Stewart M, Zelevinsky K: Nurse-staffing levels and the quality of care in hospitals. N Engl J Med 2002, 346:1715.

58. Connecting for Health: Assistive technology: helping patients to monitor vital signs at home [http://www.connectingforhealth.nhs.uk/factsandfiction/ patientcases/telehealth?searchterm=technology]

59. Cale DD: A new perspective on patient monitoring. Nurs Manage 2007, $38: 24$.

60. Sudano I, Flammer AJ, Hermann F, Syburra T, Kaiser P, Hirt A, Hermann M, Corti R, Ruschitzka F, Zund G, Noll G: Auricall. A new device for a noninvasive, wireless, continuous monitoring of oxygen saturation and heart rate in patients with heart failure. Int J Cardio/ 2008, 129:141-143.

61. Kisner D, Wilhelm MJ, Messerli MS, Zünd G, Genoni M: Reduced incidence of atrial fibrillation after cardiac surgery by continuous wireless monitoring of oxygen saturation on the normal ward and resultant oxygen therapy for hypoxia. Eur I Cardiothorac Surg 2008, 35:111-115.

62. Williams N: Concerns mount over genetics and insurance. Curr Biol 2001, 11:375-376.

63. Nakamoto H, Nishida E, Ryuzaki M, Sone M, Suzuki H, Yoshimoto M, Itagaki K. Effect of telmisartan and amlodipine on home blood pressure by monitoring newly developed telemedicine system: Monitoring test by using telemedicine. Telmisartan's effect on home blood pressure (teltelbosu). Clin Exp Hypertens 2008, 30:57-67.

doi:10.1186/cc9208

Cite this article as: Nangalia $V$, et al: Health technology assessment review: Remote monitoring of vital signs - current status and future challenges.

Critical Care 2010, 14:233. 